\title{
Narrow-band imaging versus white light for the detection of proximal colon serrated lesions: a randomized, controlled trial
}

Douglas K. Rex, Ryan Clodfelter, Farrah Rahmani, Hala Fatima, Toyia N. James-Stevenson, John C. Tang, Hak Nam Kim, Lee McHenry, Charles J. Kahi, Nicholas A. Rogers, Debra J. Helper, Sashidhar V. Sagi, William R. Kessler, John M. Wo, Monika Fischer, Paul Y. Kwo

\begin{abstract}
Background: The value of narrow band imaging (NBI) for detecting serrated lesions is unknown.
\end{abstract}

Objective: Assess NBI for detection of proximal colon serrated lesions.

Design: Randomized controlled trial.

Setting: Two academic hospital outpatient units.

Patients: 800 outpatients age $\geq 50$ years with intact colons undergoing routine screening, surveillance or diagnostic examinations.

Interventions: Randomization to colon inspection in NBI vs. white light (WL); colonoscopy.

Main outcome measurements: Number of serrated lesions (sessile serrated polyps plus hyperplastic polyps) proximal to the sigmoid colon.

This is the author's manuscript of the article published in final edited form as:

Rex, D. K., Clodfelter, R., Rahmani, F., Fatima, H., James-Stevenson, T. N., Tang, J. C., ... Kwo, P. Y. (2016). Narrow-band imaging versus white light for the detection of proximal colon serrated lesions: a randomized, controlled trial. Gastrointestinal Endoscopy, 83(1), 166-171. https://doi.org/10.1016/j.gie.2015.03.1915 
Results: Mean inspection times for the whole colon and proximal colon were equal for the NBI and WL groups. There were 204 proximal colon lesions in the NBI group and 158 in the WL group $(\mathrm{p}=0.085)$. Detection of conventional adenomas was comparable in the two groups.

Limitations: Lack of blinding, endoscopic estimation of polyp location.

Conclusions: NBI may increase the detection of proximal colon serrated lesions, but the result in this trial did not reach significance. Additional study of this issue is warranted.

ClinicalTrials.gov Identifier: NCT01572428 
Introduction

The serrated class of colorectal polyps and flat lesions includes hyperplastic polyps, sessile serrated adenomas (also known as sessile serrated polyps and abbreviated here as SSA/P) and traditional serrated adenomas (TSA) [1]. SSA/P and TSA are both considered precancerous lesions, but SSA/P is much more common, making SSA/P the most important lesion in the serrated class. SSA/P is the precursor of perhaps 20 to $30 \%$ of colorectal cancers [2-4]. Cancers arising through the serrated pathway occur predominantly in the proximal colon and are hypermethylated relative to cancers arising through other pathways [1-4].

Few studies on detection of colorectal lesions have focused specifically on serrated lesions. Narrow band imaging (NBI, Olympus America Corp., Center Valley, PA) has been studied extensively for its potential to improve detection of conventional adenomas [5 6]. Studies using NBI were largely negative for any effect of NBI improving detection, though one study suggested that NBI produced a learning effect in low-level detectors [7]. The latest generation of Olympus colonoscopes (designated the 190 series or Exera III) has NBI with brighter illumination compared to NBI in the 180 series [8]. In an initial study, the 190 series NBI provided improved detection of conventional adenomas compared to white light [9]. A recent study of NBI using high definition 180 series colonoscopes tested detection versus white light in 52 patients with serrated polyposis syndrome [10]. In a randomized crossover multicenter study, the miss rate for white light was $29 \%$ versus $20 \%$ for NBI $(p=0.065)$. 
In this report we describe the first controlled trial testing whether NBI in 190 series Olympus colonoscopes improves detection of proximal serrated colorectal polyps during routine colonoscopy.

Methods

This was a randomized controlled trial comparing detection of serrated colorectal lesions proximal to the sigmoid colon with NBI versus white light. The study was approved by the Institutional Review Board at Indiana University Health on March 23 ${ }^{\text {rd }}$, 2011. All study subjects provided informed consent for participation.

The study was conducted in 2 hospital based outpatient departments, one located adjacent to Indiana University Hospital, and the other located just north of Indianapolis in Carmel, Indiana. Patients were recruited as they presented for colonoscopy. Both endoscopy sites are staffed only by attending gastroenterologists in our practice group.

Inclusion criteria included age $\geq 50$ years, and colonoscopy for screening, surveillance, or diagnostic indications. Exclusion criteria were inpatients and patients with inflammatory bowel disease, polyposis syndromes, previous surgical resection of any portion of the colon or rectum, age $>75$ years, and referral for resection of a previously diagnosed colorectal polyp or treatment of any known colorectal lesion. 
Patients were recruited between May 19, 2011 and July 7, 2014.

All patients underwent bowel preparation using split- dose FDA approved preparations or a homemade preparation consisting of split dose PEG-3350 (MiraLAX), bisacodyl, and magnesium citrate. After insertion of the colonoscope to the cecum, the colonoscopist made a decision to randomize the patient based on the quality of the bowel preparation. Patients with preparations that were considered too difficult to correct with intraprocedural washing procedures (particularly if randomization would be to NBI) were excluded prior to randomization. There was no systematic attempt to identify polyps during insertion, but polyps detected could be removed during insertion at the endoscopist's discretion. All such polyps were counted as detections for the light the patient was ultimately assigned to for the withdrawal phase.

If the preparation was considered adequate to allow examination in NBI, randomization was performed by opening a sealed envelope. The randomization order was determined using a computer generated sequence in block sizes of ten. Research assistants including RC and FR enrolled participants and assigned them to interventions.

Once the randomization assignment was announced, the inspection was carried out entirely using the assigned light. If a lesion was detected, the colonoscopist could change from NBI to white light and vice versa at their discretion to interrogate the lesion and perform polypectomy. Once the polypectomy was completed and the polyp retrieved, the endoscopist returned to the assigned light for inspection. A study assistant measured the "inspection time" using a stopwatch. The 
watch was started at the moment that cecal inspection began, and was stopped at a verbal command from the endoscopist whenever inspection stopped for suctioning, washing, or identification of a lesion. The watch was restarted as soon as inspection was restarted.

The endoscopist was instructed to target 4 minutes of inspection time from the cecum to the splenic flexure, and 4 minutes of inspection time from the splenic flexure to the end of the examination. For timing of inspection, the endoscopist determined when the splenic flexure was reached.

Each lesion was resected and placed in a separate bottle for pathologic examination.

Size and location in the colon were estimated by the colonoscopist using endoscopic criteria. The colonoscopies were performed by 14 board certified gastroenterologists, all of whom were attendings in the division of gastroenterology.

The study sponsors had no role in the study design, conduct of the study, analysis of the data, manuscript preparation or revision.

Statistical analysis

The primary end point was the number of lesions in the serrated class proximal to the sigmoid colon per patient. Secondary endpoints were the percentage of patients with one or more serrated lesions proximal to the sigmoid colon, the number of conventional adenomas per patient, and the 
percent of patients with one or more conventional adenomas. Based on a database that records all polyps with their size, location, histology, and the performance of the physicians who would be participating in the trial, we estimated a mean of 0.15 serrated lesions proximal to the sigmoid colon per patient aged $\geq 50$ years. With a sample size of 394 patients per group, the study had $80 \%$ power to detect a difference between 0.15 and 0.25 proximal colon serrated lesions per patient, assuming a two-sample t-test conducted at a 5\% significance level and a standard deviation of 0.5. Estimated rates of serrated lesions and the standard deviation were derived from prior studies of detection of serrated lesions at our center [11 12]. We targeted 800 total randomized patients. Demographic and baseline factors were compared using chi-square tests and Wilcoxon rank-sum tests. The numbers of proximal colon serrated lesions and the numbers of adenomas were compared between the NBI and white light arms using negative binomial regression models.

\section{Results}

A total of 898 patients were recruited into the study and provided informed consent to participate. There were 94 patients who were excluded prior to randomization because of inadequate preparation to allow good visualization with NBI. Eight hundred patients were randomized and completed the trial, including 399 in the NBI arm and 401 in the white light arm. Figure 1 shows the flow of patients from assessment for eligibility through randomization.

Table 1 shows demographic factors, smoking history, American Society of Anesthesiology risk class, procedure indication, bowel preparation used, and procedure bowel preparation cleansing 
quality. There were no differences between the study arms in any of these factors. Also, there was no difference in the number of patients in the two study arms for any individual endoscopist.

Table 2 demonstrates that bowel preparation quality and inspection times were similar for the two study arms. Total procedural time was longer with NBI 24.73 (standard error 0.40) minutes versus 22.62 (SE $0.4 ; \mathrm{p}<0.0001$ ). These differences were accounted for by longer time to perform clean up maneuvers and the numerically greater number of polyps in the NBI arm. Our data collection did not allow us to determine the relative contribution of those effects. The mean time between completion of the preparation and initiation of the procedure was 6.12 (SD 2.41) hours in the NBI arm and 6.10 (SD 1.99) in the white light arm.

Table 2 shows the results with regard to detection. All categories of proximal colon serrated lesions and conventional adenomas were numerically more common in the NBI group. For the primary end point of the number of serrated lesions proximal to the sigmoid colon of any size, there was a trend in favor of NBI (204 versus 158 lesions; $\mathrm{p}=0.085$ ) but the difference did not reach significance. For proximal colon serrated lesions $>5 \mathrm{~mm}$ in size, the larger number detected with NBI reached significance Table 2). There were two SSA/Ps with cytological dysplasia in the white light arm and none in the NBI arm. There were no important differences between the study arms in detection of conventional adenomas (Table 2). To check for a learning effect from NBI [7], we examined detection over time during the study for all groups of lesions (Table 2), and no significant time trends were identified overall or for individual examiners. 
Discussion

We describe a randomized controlled clinical trial designed to determine whether narrow-band imaging improves detection of lesions in the serrated class proximal to the sigmoid colon. The results showed a trend toward more proximal colon serrated lesions with NBI. We made no attempt to determine whether the number of SSA/Ps detected was higher with NBI, since in our experience this would require review of pathology slides by experts outside our institution, and even expert review of pathology slides for the issue of SSA/P vs hyperplastic histology is subject to marked interobserver variation [13-15]. Since the differences in detection of serrated lesions were more pronounced with larger lesions in the serrated class, and SSA/Ps are on average larger than hyperplastic polyps [12 14], our results suggest that NBI might result in better detection of SSA/Ps. Given that the total number of conventional adenomas was nearly identical between the two study arms (Table 2), we consider that there were no important differences between the study arms in detection of conventional adenomas. Our results suggest no downside from using NBI with regard to detection of conventional adenomas. We checked for evidence of a learning effect from NBI, as seen by Adler et al. for detection of conventional adenoma. We did not see significant trends in detection for any group of lesions over time. Thus, we could not verify a learning effect on detection from NBI.

A previous study in serrated polyposis suggested that NBI may provide better detection of lesions in the serrated class [10]. The current study is the first study we are aware of to target detection of proximal colon serrated lesions as the primary endpoint in routine colonoscopy 
patients. Strengths of this study include its large size, randomized design, and targeted inspection times which were equal between the study arms. We successfully forced inspection times to be equal between the study arms. Failure to force inspection times to be equal can bias one study arm over another with regard to detection [16]. In a prior study comparing NBI to white light using 180 series colonoscopes we tried to force equal inspection times but were unsuccessful, with NBI inspection times averaging 30 seconds or longer than white-light, a difference that was highly statistically significant [17]. Our interpretation of that result was that the darkness of the $180 \mathrm{NBI}$ image required moving the colonoscope tip closer to the mucosal surfaces to achieve adequate imaging, a process that took longer than white-light inspection and prevented equal inspection times without frank loitering with white light. In the 190 series NBI illumination is brighter, and forcing equal inspection times was successfully achieved. Thus, brighter illumination in the 190 series NBI is a significant achievement compared to $180 \mathrm{NBI}$.

Our study has limitations. First, the endoscopists were not blinded to the type of light being used. This is a limitation of all detection studies. Accurate results depend on the best efforts of the endoscopists to eliminate any bias toward the outcome. Second, we used endoscopic criteria to determine polyp size and location. Estimation of polyp size by endoscopists is notoriously inaccurate. However, we are aware of no data suggesting that this estimation is more or less inaccurate using NBI compared to white light. Colonic location estimates by endoscopy are also notoriously inaccurate, but would not be expected to be different in NBI vs white light. The use of any separation of the colon into segments is a disadvantage in a detection study, but we considered that we had to do this to avoid including detection of recto-sigmoid hyperplastic polyps, which are considered to not be pre-malignant, and would not be a clinically important 
endpoint. Next, we did not make SSA/P an endpoint of the study, but rather the entire serrated class (hyperplastic plus SSA/P). While we would have preferred to make SSA/P the primary endpoint, the limitations of pathologic assessment seemed to make this impractical at the present time. Finally, we found that procedures were on average about 2 minutes longer with NBI compared to white light, but we cannot say whether the longer procedures resulted from longer time to clean up with NBI or longer time to perform the greater number of polypectomies with NBI, because we did not separate these times in our measurements. We wish to emphasize that longer clean up times are not the same as longer inspection times, and that longer cleaning with NBI is because pools of retained fluid and debris appear to take longer to clean up in NBI than white light because mucus and fluid are hard to "see through" in NBI. The colonoscopists in our study were all academic gastroenterologists, and 12 of 14 did not have a research interest in colonoscopy. Thus, the generalizability of our results is uncertain.

In summary, examination of the colon with NBI in Olympus 190 series colonoscopes in routine patients undergoing colonoscopy resulted in a trend toward detection of more proximal colon serrated lesions. Detection of conventional adenomas by NBI and white light were similar. We recommend that clinicians evaluate the use of NBI in Olympus 190 colonoscopes for detection of serrated lesions, and that other investigators develop studies directed to detection of the serrated class of colorectal lesions. 
Figure Legend

Figure 1. Flow of study subjects from evaluation of patients for eligibility to completion of the study. 


\section{References}

1. Rex DK, Ahnen DJ, Baron JA, et al. Serrated lesions of the colorectum: review and recommendations from an expert panel. Am J Gastroenterol 2012;107(9):1315-29 doi: 10.1038/ajg.2012.161[published Online First: Epub Date]|.

2. Samowitz WS, Albertsen H, Herrick J, et al. Evaluation of a large, population-based sample supports a CpG island methylator phenotype in colon cancer. Gastroenterology 2005;129(3):837-45 doi: 10.1053/j.gastro.2005.06.020[published Online First: Epub Date]|.

3. Hawkins N, Norrie M, Cheong K, et al. CpG island methylation in sporadic colorectal cancers and its relationship to microsatellite instability. Gastroenterology 2002;122(5):1376-87 doi: 10.1053/gast.2002.32997[published Online First: Epub Date]|.

4. Toyota M, Ahuja N, Ohe-Toyota M, et al. CpG island methylator phenotype in colorectal cancer. Proc Natl Acad Sci U S A 1999;96(15):8681-6

5. Dinesen L, Chua TJ, Kaffes AJ. Meta-analysis of narrow-band imaging versus conventional colonoscopy for adenoma detection. Gastrointest Endosc 2012;75(3):604-11 doi: 10.1016/j.gie.2011.10.017[published Online First: Epub Date]|.

6. Pasha SF, Leighton JA, Das A, et al. Comparison of the yield and miss rate of narrow band imaging and white light endoscopy in patients undergoing screening or surveillance colonoscopy: a metaanalysis. Am J Gastroenterol 2012;107(3):363-70; quiz 71 doi: 10.1038/ajg.2011.436[published Online First: Epub Date]|.

7. Adler A, Pohl H, Papanikolaou IS, et al. A prospective randomised study on narrow-band imaging versus conventional colonoscopy for adenoma detection: does narrow-band imaging induce a learning effect? Gut 2008;57(1):59-64 doi: 10.1136/gut.2007.123539[published Online First: Epub Date]|.

8. Bade K, MacPhail ME, Johnson CS, et al. New colonoscope technology: impact on image capture and quality and on confidence and accuracy of endoscopy-based polyp discrimination. Endoscopy 2014;46(3):172-8 doi: 10.1055/s-0033-1353602[published Online First: Epub Date]|.

9. Leung WK, Lo OS, Liu KS, et al. Detection of colorectal adenoma by narrow band imaging (HQ190) vs. high-definition white light colonoscopy: a randomized controlled trial. Am J Gastroenterol 2014;109(6):855-63 doi: 10.1038/ajg.2014.83[published Online First: Epub Date]|.

10. Hazewinkel Y, Tytgat KM, van Leerdam ME, et al. Narrow-band imaging for the detection of polyps in patients with serrated polyposis syndrome: a multicenter, randomized, back-to-back trial. Gastrointest Endosc 2014 doi: 10.1016/j.gie.2014.06.043[published Online First: Epub Date]|.

11. Kahi CJ, Hewett DG, Norton DL, et al. Prevalence and variable detection of proximal colon serrated polyps during screening colonoscopy. Clin Gastroenterol Hepatol 2011;9(1):42-6 doi: 10.1016/j.cgh.2010.09.013[published Online First: Epub Date]|.

12. Abdeljawad K, Vemulapalli KC, Kahi CJ, et al. Sessile serrated polyp prevalence determined by a colonoscopist with a high lesion detection rate and an experienced pathologist. Gastrointest Endosc 2014 doi: 10.1016/j.gie.2014.04.064[published Online First: Epub Date]|.

13. Payne SR, Church TR, Wandell M, et al. Endoscopic detection of proximal serrated lesions and pathologic identification of sessile serrated adenomas/polyps vary on the basis of center. Clin Gastroenterol Hepatol 2014;12(7):1119-26 doi: 10.1016/j.cgh.2013.11.034[published Online First: Epub Date]|.

14. Tinmouth J, Henry P, Hsieh E, et al. Sessile serrated polyps at screening colonoscopy: have they been under diagnosed? Am J Gastroenterol 2014;109(11):1698-704 doi: 10.1038/ajg.2014.78[published Online First: Epub Date]|.

15. Khalid O, Radaideh S, Cummings OW, et al. Reinterpretation of histology of proximal colon polyps called hyperplastic in 2001. World J Gastroenterol 2009;15(30):3767-70 doi: 10.3748/wjg.15.3767[published Online First: Epub Date]|. 
16. Leufkens AM, DeMarco DC, Rastogi A, et al. Effect of a retrograde-viewing device on adenoma detection rate during colonoscopy: the TERRACE study. Gastrointest Endosc 2011;73(3):480-9 doi: 10.1016/j.gie.2010.09.004[published Online First: Epub Date]|.

17. Rex DK, Helbig CC. High yields of small and flat adenomas with high-definition colonoscopes using either white light or narrow band imaging. Gastroenterology 2007;133(1):42-7 
Table 1. Comparison of demographic features and baseline factors between the narrow band imaging (NBI) and white light arms.

\begin{tabular}{|c|c|c|c|}
\hline & NBI $(n=399)$ & White Light $(\mathrm{n}=401)$ & $\mathrm{p}$ \\
\hline Age (years) & 61.08 & 61.41 & 0.517 \\
\hline $\begin{array}{l}\text { Time from end of } \\
\text { prep to procedure start } \\
\text { (hours) }\end{array}$ & 6.12 & 6.10 & 0.490 \\
\hline Male N (\%) & $183(46)$ & $161(40)$ & 0.103 \\
\hline Race N (\%) & & & 0.547 \\
\hline white & $339(85)$ & $329(82)$ & \\
\hline black & $54(14)$ & $63(16)$ & \\
\hline other & $4(1)$ & $3(1)$ & \\
\hline Tobacco use (\%) & & & 0.418 \\
\hline current & $53(13)$ & $44(11)$ & \\
\hline past & $130(33)$ & $123(31)$ & \\
\hline never & $216(54)$ & $234(58)$ & \\
\hline ASA risk class & & & 0.551 \\
\hline 1 & $53(13)$ & $63(16)$ & \\
\hline 2 & $230(58)$ & $226(56)$ & \\
\hline 3 & $117(29)$ & $112(28)$ & \\
\hline Indication & & & 0.567 \\
\hline Screening & $212(53)$ & $203(51)$ & \\
\hline Surveillance & $149(37)$ & $162(40)$ & \\
\hline Other & $38(10)$ & $36(9)$ & \\
\hline
\end{tabular}

$\mathrm{N}$ : number of patients ASA: American Society of Anesthesiologists 
Table 2. Comparison of bowel preparation scores, inspection times, and study outcomes.

\begin{tabular}{|c|c|c|c|}
\hline & NBI & White Light & $\mathrm{p}$ \\
\hline $\begin{array}{r}\text { Preparation quality } \\
\text { excellent } \\
\text { good } \\
\text { fair }\end{array}$ & $\begin{array}{r}179(45)^{*} \\
200(50) \\
18(5)\end{array}$ & $\begin{array}{r}202(51) \\
175(44) \\
23(6)\end{array}$ & 0.161 \\
\hline $\begin{array}{l}\text { Inspection time } \\
\text { proximal colon } \\
\text { distal colon }\end{array}$ & $\begin{array}{r}3.82(0.05)^{* *} \\
3.61(0.05)\end{array}$ & $\begin{array}{l}3.88(0.05) \\
3.65(0.05)\end{array}$ & $\begin{array}{l}0.197 \\
0.419 \\
\end{array}$ \\
\hline $\begin{array}{l}\text { Serrated lesions } \\
\text { proximal to sigmoid } \\
\qquad \begin{array}{r}\text { Any size } \\
>5 \mathrm{~mm} \\
\geq 10 \mathrm{~mm}\end{array}\end{array}$ & $\begin{array}{r}204(0.51)+ \\
95(0.24) \\
39(0.10)\end{array}$ & $\begin{array}{r}158(0.39) \\
59(0.15) \\
20(0.05)\end{array}$ & $\begin{array}{l}0.085 \\
0.027 \\
0.049\end{array}$ \\
\hline $\begin{array}{l}\text { Patients with at least } 1 \\
\text { serrated lesion } \\
\text { proximal to sigmoid } \\
\text { Any size } \\
>5 \mathrm{~mm} \\
\geq 10 \mathrm{~mm}\end{array}$ & $\begin{array}{r}105(26)^{*} \\
60(15) \\
25(6)\end{array}$ & $\begin{array}{r}107(27) \\
45(11) \\
19(5)\end{array}$ & $\begin{array}{l}0.906 \\
0.110 \\
0.343\end{array}$ \\
\hline $\begin{array}{r}\text { Conventional } \\
\text { adenoma entire colon } \\
\text { Total number of } \\
\text { adenomas/ (adenomas } \\
\text { per patient) } \\
\text { All sizes } \\
>5 \mathrm{~mm} \\
\geq 10 \mathrm{~mm}\end{array}$ & $\begin{array}{r}438(1.1) \\
110(0.28) \\
29(0.07)\end{array}$ & $\begin{array}{r}434(1.08) \\
90(0.22) \\
22(0.05)\end{array}$ & $\begin{array}{l}0.894 \\
0.246 \\
0.383\end{array}$ \\
\hline $\begin{array}{r}\text { Patients with a least } 1 \\
\text { conventional adenoma } \\
\text { Any size }(\%) \\
>5 \mathrm{~mm} \\
\geq 10 \mathrm{~mm}\end{array}$ & $\begin{array}{r}202(51)^{*} \\
84(21) \\
25(6)\end{array}$ & $\begin{array}{r}189(47) \\
61(15) \\
18(4)\end{array}$ & $\begin{array}{l}0.323 \\
0.032 \\
0.265\end{array}$ \\
\hline
\end{tabular}

* number of patients (percent)

** minutes (standard error)

+ number of lesions (number of lesions per patient) 